\title{
Do the Corticospinal and Corticobulbar Tracts Mediate Functions in the Human Newborn?
}

\author{
Harvey B. Sarnat
}

\begin{abstract}
Unlike the numerous dispersed bulbospinal pathways that are already well myelinated at term, the more compact corticospinal and corticobulbar tracts are only beginning their myelination cycle in late gestation and do not complete it until two years of age. During this same period, these pathways also develop extensive ramification of terminal axonal segments, growth of collateral axons, and proliferation of synapses. Despite their immaturity in the fullterm human newborn, several proposed functions may be attributed to the descending pathways from the neonatal cerebral cortex: a) a contribution to the differential development of passive muscle tone and resting postures; in general they function as an antagonist to the "subcorticospinal pathways" in mediating proximal flexion and distal extension, except for the rubrospinal tract which is probably synergistic with the corticospinal tract; b) enhancement of tactile reflexes originating in the brainstem and spinal cord, including suck and swallow; c) relay of epileptic activity of cortical origin; d) inhibition of complex stereotyped motor reflexes including many phenomena formerly termed "subtle seizures"; e) a possible influence on muscle maturation, particularly in relaying cerebellar impulses that modify the histochemical differentiation of myofibres. However, the bulbospinal tracts are probably more influential on muscle development. The corticospinal and corticobulbar tracts subserve different needs in the newborn than at older ages, but are functionally important pathways even at birth.
\end{abstract}

RÉSUMÉ: Les voies cortico-spinales et cortico-bulbaires jouent-elles un rôle fonctionnel chez le nouveau-né? Contrairement aux nombreuses voies bulbo-spinales dispersées qui sont déjà bien myélinisées chez le nouveau-né à terme, les voies cortico-spinales et cortico-bulbaires plus compactes n'en sont qu'au début de leur cycle de myélinisation pendant les dernières semaines de la vie foetale et ne complètent ce cycle que deux ans après la naissance. Pendant cette période, il se produit, au niveau de ces voies, un développement extensif des ramifications des segments terminaux des axones, une croissance des axones collatéraux et une prolifération des synapses. Malgré leur immaturité chez le nouveau-né à terme, plusieurs fonctions peuvent être attribuées aux voies descendantes provenant du cortex cérébral néonatal. Parmi ces fonctions, mentionnons: a) une contribution au développement du tonus musculaire passif et de la posture au repos; en général elles ont une fonction antagoniste des voies subcortico-spinales dans la médiation de la flexion proximale et de l'extension distale, sauf pour ce qui est du faisceau rubro-spinal qui a une fonction synergique de celle du faisceau cortico-spinal; b) un renforcement des réflexes tactiles qui proviennent du tronc cérébral et de la moëlle épinière, incluant les réflexes de succion et de déglutition; c) un relais de l'activité épileptique d'origine corticale; d) une inhibition de réflexes moteurs complexes, stéréotypés, incluant plusieurs phénomènes reconnus comme des "convulsions frustres"; e) une influence possible sur la maturation musculaire, particulièrement par le relais de l'influx cérébelleux qui modifie la différentiation histochimique des fibres musculaires. Cependant, les voies bulbo-spinales ont vraisemblablement un rôle plus important dans le développement musculaire au cours de la vie foetale. Bien que les voies cortico-spinales et cortico-bulbaires servent à des fins différentes chez le nouveau-né et chez l'individu plus âgé, elles sont déjà d'une grande importance fonctionnelle à la naissance.

Can. J. Neurol. Sci. 1989; 16:157-160

The corticospinal tract (CST), the largest descending pathway from the brain to the spinal cord, is barely myelinated at term. By light microscopy and special stains, myelin is demonstrated only as far caudally as the cerebral peduncles, ${ }^{1}$ and by electron microscopy only one or two turns of myelin are seen to ensheath pyramidal tract axons in the medulla and none in the spinal cord. The myelination of the CST is not completed until two years of age. ${ }^{2}$

Axons of the CST and the corticobulbar tract (CBT) originate from large pyramidal cells in the motor cortex, supplemented by fibres from widespread areas of frontal, parietal, temporal, and occipital lobes. The frontal lobe (i.e. motor cortex)

From the Departments of Paediatrics, Pathology and Clinical Neurosciences, University of Calgary Faculty of Medicine, Calgary Received June 22, 1988. Accepted in final form February 22, 1989

Reprint requests to: Dr. H.B. Sarnat, Alberta Children's Hospital, 1820 Richmond Road S.W., Calgary, Alberta, Canada T2T 5C7 
is the origin of most fibres that terminate on motor neurons, while corticospinal fibres from somatosensory cortex end in the dorsal horn of the spinal cord, in the monkey. ${ }^{3-6}$ In the rat, transitory corticospinal connections from cortical areas outside the pericentral regions, particularly from the occipital lobe, are present postnatally but disappear with cerebral maturation. ${ }^{7}$

Many other tracts originate in brainstem centres and also descend to the spinal cord. They are not as compact as the pyramidal tract, but their individual small sizes are deceptive and they have spinal cord ramifications at least as extensive as those of the CST. Some, such as the rubrospinal tract, may extend only as far as upper cervical segments in man, ${ }^{8}$ though this evidence is incomplete and in the monkey the rubrospinal tract extends throughout the spinal cord. The olivospinal pathway is found in lower mammals, but has not been demonstrated in the cat, monkey, or human. The descent of bulbospinal pathways within the brainstem is often divided into medial (ventromedial) and lateral subdivisions of each tract: vestibulospinal, reticulospinal, and tectospinal. ${ }^{9}$ Additional important descending fibres to the spinal cord arise from the midline raphé nuclei of the medulla and pons and from the locus coeruleus. ${ }^{10}$

Most of the bulbospinal pathways are already well myelinated at birth and are probably more important to neurological function in the perinatal period than at any other time in life. As the CST progressively acquires more myelin and more terminal synapses, its functional importance in voluntary motor control usurps the largely reflexive functions of the bulbospinal tracts. The classical clinical signs of CST damage in adults, extensor plantar responses, loss of independent voluntary finger movements, and overly brisk stretch reflexes, are normal findings in the term neonate. The question of whether the CST and CBT indeed subserve any physiological functions in the neonatal period is often posed by observations of clinical neurological deficits in neonates who have suffered insults to the cerebral cortex but who show no evidence of brainstem impairment. If the CST and CBT do have clinical expression in motor function and behaviour in the neonatal period, that expression is not necessarily the same as might occur months later when myelination and synaptic contacts within the spinal cord are more complete, and other aspects of cerebral maturation also have progressed. Lawrence and Hopkins have shown in the monkey that fine, fractionated movement is related to the development of corticomotoneuronal connections that mainly arise in the frontal lobes. In the monkey, these synapses are few at birth and do not reach a density similar to the adult until 8 months of age, ${ }^{5}$ and the formation of these synapses is almost certainly even more protracted in the human infant. The monosynaptic stretch reflex in the human spinal cord is functional as early as 25 weeks gestation, with a gradual shortening of the $\mathrm{H}$-reflex until term. ${ }^{11}$

The following manifestations are proposed as likely physiological expressions of CST and CBT functions in the human newborn. Many of these proposed functions remain speculative because of the incompleteness of data, but they are consistent with currently available information based on observations of human neonates and nonhuman species.

Contribution to the differential development of passive extensor and flexor muscle tone and resting postures All descending motor tracts may be functionally grouped as three physiological pathways in terms of composite motor function and modulation of motor neuron activity. Lawrence and Kuypers identified these three groups of tracts in the monkey from unilateral and bilateral lesions of the pyramidal tract, and by selective interruption of bulbospinal tracts within the brainstem after recovery from the pyramidal tractotomies. 9,12 They designated the three functional descending pathways as medial (ventromedial) subcorticospinal, lateral subcorticospinal, and corticospinal. The medial subcorticospinal pathway functions as the basic system by which the brain exerts control over movement in the adult as well as the neonate, particularly extension of the trunk and limb girdles to provide for erect posture; it is only minimally involved with distal motility. Interruption of the lateral subcorticospinal pathway, by contrast, reveals that it mediates flexion of extended limbs and is crucial for distal limb and hand movements. The lateral subcorticospinal pathway thus supplements the control of gross axial and limb movements with the capacity for independent use of an extremity, particularly the hand. The corticospinal tract subserves a control similar to that of both the medial and lateral subcorticospinal pathways, but in addition it allows further fractionation of movements such as individual finger control. The data of Lawrence and Kuypers further imply that the subcorticospinal pathways mainly provide for proximal extension and distal flexion. The function of the corticospinal tract as a fractionator of fine finger movements is not evident in early infancy. However its apparently antagonistic influence in favour of proximal flexor and distal extensor tone in is very much in evidence in the term neonate.

The myelination sequence of these pathways may partially explain the development of muscle tone and postures in the premature infant. ${ }^{13}$ Fibres of the medial subcorticospinal pathways myelinate earliest, at 24-30 weeks gestation; those of the lateral subcorticospinal pathways are somewhat more delayed at 28-34 weeks; corticospinal fibres do not begin to myelinate until nearterm. 1,2 In the preterm infant, axial extension precedes flexion, but finger flexion precedes extension except in the very young preterm infant who lies extended because of total flaccidity and weakness.

Pathological conditions are even more illustrative of the antagonistic balance between flexors and extensors controlled by the subcorticospinal and corticospinal pathways. If the CST is suddenly impaired as with perinatal asphyxia, the cerebral cortex generally being less resistant to hypoxia than the brainstem, the infant assumes characteristic postures familiar to all clinicians involved with neonatal care: strong distal flexion with adduction of the thumbs and flexion of fingers and toes, and proximal extension involving arching of the back and extension of the hips. These postures probably reflect the influence of the subcorticospinal pathways, lacking antagonism by the CST. ${ }^{13}$

The cerebral cortex may affect antagonistic muscle tone via the subcorticospinal pathways as well as the large CST. Corticobulbar fibres project to many nonmotor brainstem centres in addition to motor nuclei. Brainstem nuclei are released from either inhibitory or facilitatory cerebral control mediated by the CBT whenever cerebral cortical function is selectively impaired. In addition to projections from motor cortex upon the red nucleus, vestibulai nuclei and reticular formation, a powerful influence of limbic structures of the forebrain, particularly 
the hippocampal formation, is relayed by direct connections to the raphé nuclei and locus coeruleus. ${ }^{10}$ The latter structures then project caudally to the spinal cord without intermediate synapses.

In this regard, the so-called "tonic seizures" of preterm infants with intraventricular haemorrhages are probably not true epileptic phenomena but rather episodes of decerebration. ${ }^{14}$

Enhancement of tactile reflexes Tactile reflexes are those with sensory afferent segments from cutaneous or mucus membranous fields and somatic motor efferent segments of the reflex arc. Examples of neonatal tactile reflexes are the trunk incurvation reflex of Galant, the grasp reflex (but not the traction response, a stretch reflex), finger extension with dorsal stroking of the fingers, and the rooting reflex. However, contact placing in the kitten is not dependent upon sensorimotor cortex in the first postnatal month. ${ }^{15,16}$ This function appears to be performed by the red nucleus and rubrospinal tract. ${ }^{16}$ There is an extensive sprouting of corticocorubral synapses in neonatal kittens ${ }^{16}$ and an increased efficacy of the corticorubrospinal system when augmented by lesions of the deep cerebellar nuclei associated with the vermis. ${ }^{15}$ Corticorubral projections in the monkey arise from the precentral gyrus (i.e. motor cortex) and are arranged in a somatotopic sequence. ${ }^{17}$ The cortico-rubro-spinal pathway may be important in contact placing and also in some conditioned reflexes of motor skills. ${ }^{18}$ Because of its location in the upper midbrain, the red nucleus is likely to be impaired sooner than centres in the pons and medulla oblongata in the course of rostrocaudal progression of cerebral depression with metabolic insults.

Most tactile reflexes in humans develop in midgestation, the Galant reflex appearing at 24 weeks gestation, 19 and the finger extension reflex by 28 weeks. ${ }^{20}$ Cutaneous afferent fibres affect muscle tone of proximal lower limb flexors and extensors via the vestibulospinal tracts, ${ }^{21}$ which contribute to both the medial and lateral subcorticospinal pathways. The most important tactile reflexes of the neonate are those of suck and swallow, which develop early, as shown by real-time fetal sonography.

Tactile reflexes are fundamentally spinal cord and brainstem reflexes without relay through the cerebral cortex. However, the cerebral cortex exerts a reinforcing or facilitatory influence, and removal of CST and CBT function, as in perinatal asphyxia, appears to raise the threshold of tactile reflexes to an extent that they become ineffective. ${ }^{13} \mathrm{~A}$ weak suck, poor feeding, and impaired coordination of swallowing are findings common to many disturbances of cerebral cortical (i.e. CST/CBT) functions in the newborn, regardless whether the aetiology be hypoxia, meningitis, subarachnoid haemorrhage, or hydrocephalus. Occasionally an infant lacks a cerebral cortex developmentally, as in hydranencephaly, or has a severely defective cerebral cortex as with severe forebrain malformations. Such infants may suck and swallow surprisingly well. In these cases, the brainstem tactile reflexes function as pure subcortical phenomena, never having been modified by the development of suprasegmental reinforcement. Once cortical enhancement of the tactile reflexes has developed, however, the sudden removal of this enhancement becomes clinically expressed as impaired tactile reflexes. The reinforcement of suck and swallow reflexes by the corticobulbar tract remains speculative until confirmed by additional evidence, but the extensive clinical observations and neu- ropathological corroboration of the site of lesions suggest that this is the probable mechanism.

Relay of epileptic discharges The anatomical sites of origin of neonatal seizures and the pathways over which they are propagated are topics of continuing debate. Cases of seizures occurring in atelencephalic human infants are well documented, in which seizures must have been generated by subcortical structures. ${ }^{22}$ Other evidence for a subcortical origin of some human neonatal seizures also is strong. ${ }^{23}$ Myoclonic seizures of spinal cord origin were even noted by Sherrington a century ago in his classical experiments of cervically transected cats. Most human neonatal seizures are focal or multifocal, and arise in the cerebral cortex, a conclusion corroborated by electroencephalography. Such cortical epileptic phenomena are very likely transmitted to spinal motor neurons by the CST and to facial and hypoglossal nuclei by the CBT, even in preterm infants.

Inhibition of complex stereotyped motor reflexes Some phenomena, especially those termed "subtle seizures" in the newborn, probably are not true epileptic discharges but rather clinical expressions of release of complex brainstem and spinal motor reflexes from CBT and CST inhibition. ${ }^{24}$ However, paroxysmal discharges arising from deep limbic cerebral regions might not be detected by surface electrodes. The CST has an important inhibitory component. While enhancing some subcortical reflexive activity such as tactile reflexes, the tract suppresses many other reflexes. Examples include the stretch reflexes at all ages and, in the neonate, certain subcortical reflexes for stereotyped, sequential or alternating motor activities, such as cycling or swimming movements.

The CST probably does not influence muscle maturation If the CST influences the development of antagonistic muscle tone and postures in the preterm and term infant, perhaps it also plays a role in the maturation of muscle fibres themselves. Recent studies by the present author and others have disclosed that the muscle biopsies of hypotonic infants with cerebral dysplasia often exhibit a variety of aberrations in the growth and histochemical differentiation of myofibres. 25.26 Immaturity of muscle, fibre type I or II predominances of 80 percent or more, and disproportion in the growth of fibre types are the most common abnormalities. Such anomalies of muscle development are not usually found with malformations limited to the cerebral cortex, but rather accompany dysplasias of the brainstem and especially of the cerebellum.

The time of histochemical differentiation of human muscle is about 20 to 28 weeks gestation. This period coincides with myelination of the bulbospinal (i.e. subcorticospinal) pathways. At the time the CST begins its myelination cycle and has formed only a small fraction of the number of terminal synapses it will later develop, skeletal muscle is already nearly fully mature except for fibre diameter. It is therefore likely that the CST probably does not influence muscle maturation because its influence on the motor unit would be imposed too late. Abnormal suprasegmental impulses mediated by the subcorticospinal pathways, by contrast, may profoundly affect the histochemical maturation of muscle. 25,26

The particular association of cerebellar hypoplasia with aberrations of muscle maturation is of special interest because there is no known direct cerebellospinal tract in humans, though fibres from the fastigial nucleus to cervical spinal cord segments 
are described in the monkey. ${ }^{27}$ Most of the cerebellar output in humans ascends from the lateral hemispheres via the dentate nucleus to the thalamus for relay to the cerebral cortex. As with the corpus striatum, cerebellar influence on muscle tone and coordination is mainly mediated by the CST and CBT. However, some Purkinje cell axons from the vermis project directly upon the vestibular nuclei, and some axons from the fastigial and globose nuclei, subserving the vermis, terminate in the pontomedullary reticular formation and vestibular nuclei. Bulbospinal routes are therefore available to the cerebellum, particularly from the vermis, to influence motor neuron activity without intermediate synapses in the thalamus or cerebral cortex.

Hypotonia is amongst the most constant clinical findings in infants with cerebellar hypoplasia. 28 The mechanism is decreased fusimotor activity resulting in abnormal muscle spindle function. ${ }^{29}$ It is uncertain whether lesions affecting the cerebellar bulbar connections noted above are sufficient to alter bulbospinal impulses that affect muscle maturation. Whether the much larger ascending cerebello-thalamo-cortical connections actually produce this effect through the CST and CBT remains speculative. If future experimental data confirm such an effect, it probably would represent the earliest function of the corticospinal tract in the developing human nervous system.

\section{REFERENCES}

1. Rorke LB, Riggs HE. Myelination of the Brain in the Newborn. Philadelphia: JB Lippincott. 1969. 108p.

2. Yakovlev PI, Lecours A-R. The myelogenetic cycles of regional maturation of the brain. In: Minkowski A, ed. Regional Development of the Brain in Early Life. Philadelphia: FA Davis. 1967. pp. 3-70.

3. Jane JA, Yashon D, DeMyer W, et al. The contribution of the precentral gyrus to the pyramidal tract of man. J Neurosurg 1967; 26: $244-248$

4. Catsman-Berrevoets CE, Kuypers HGJM. Cells of origin of cortical projections to dorsal column nuclei, spinal cord and bulbar medial reticular formation in the rhesus monkey. Neurosci Lett 1976; 3: 245-252.

5. Lawrence DG, Hopkins DA. The development of motor control in the rhesus monkey: Evidence concerning the role of corticomotoneuronal connections. Brain 1976; 99: 235-254.

6. Jones EG, Wise SP. Size, laminar, and columnar distribution of efferent cells in the sensory-motor cortex of monkeys. J Comp Neurol 1977; 175: 391-438.

7. Stanfield BB, O'Leary DDM. The transient corticospinal projection from the occipital cortex during the postnatal development of the rat. J Comp Neurol 1985; 238: 236-248.

8. Nathan PW, Smith MC. The rubrospinal and central tegmental tracts in man. Brain 1982; 105: 233-269.
9. Lawrence DG, Kuypers HGJM. The functional organization of the motor system in the monkey. II. The effects of lesions of the descending brainstem pathways. Brain 1968; 91: 15-36.

10. Holstege JC, Kuypers HGJM. Brainstem projections to spinal motoneurons: An update. Neuroscience 1987; 23: 809-821.

11. Hakamada S, Hayakawa F, Kuno K, et al. Development of the monsynaptic reflex pathway in the human spinal cord. Dev Brain Res 1988; 42: 239-246.

12. Lawrence DG, Kuypers HGJM. The functional organization of the motor system in the monkey: I. The effects of bilateral pyramidal lesions. Brain 1968; 91: 1-14.

13. Sarnat HB. Anatomic and physiologic correlates of neurologic development in prematurity. In: Sarnat HB, ed. Topics in Neonatal Neurology. Orlando, Florida. Grune and Stratton. 1984; pp. 1-25.

14. Sarnat JB. Pathogenesis of decerebrate "seizures" in the premature infant with intraventricular hemorrhage. J Pediatr 1975; 87: 154155.

15. Amassian VE, Ross RJ. Developing role of sensorimotor cortex and pyramidal tract neurons in contact placing in kittens. J Physiol (Paris) 1978; 74: 165-184.

16. Batson DE, Amassian VE. A dynamic role of rubral neurons in contact placing by the adult cat. J Neurophysiol 1986; 56: 835856.

17. Kuypers HGJM, Lawrence DG. Cortical projections to the red nucleus and the brainstem in the rhesus monkey. Brain Res 1967; 4: 151-188.

18. Tsukahara N. Synaptic plasticity in the red nucleus and its possible behavioural correlates. $/ n$ : Cotman $\mathrm{CW}$, ed. Synaptic Plasticity. New York, London: The Guilford Press. 1985; pp. 201-227.

19. Peiper A. Cerebral Function in Infancy and Childhood. New York: Consultants Bureau; 1963.

20. Modanlou HD. Extension reflex of fingers in the newborn. Pediatr Neurol 1988; 4: 66-67.

21. Szturm T, Ireland DJ, Jell RM. Convergent effects from vestibulospinal tract and primary cutaneous afferent fibres on motoneurons to proximal lower limb flexor and extensor muscles in humans. Exp Neurol 1988; 99: 178-186.

22. Danner R, Shewmon A, Sherman MP. Seizures in an atelencephalic infant. Is the cortex essential for neonatal seizures? Arch Neurol 1985; 42: 1014-1016.

23. Camfield PR, Camfield CS. Neonatal seizures: A commentary on selected aspects. J Child Neurol 1987; 2: 244-251.

24. Mizrahi EM, Kellaway P. Characterization and classification of neonatal seizures. Neurology 1987; 37: 1837-1844.

25. Sarnat HB. Le cerveau influence-t-il le développement musculaire du foetus humain? Can J Neurol Sci 1985; 12:111-120.

26. Sarnat HB. Cerebral dysgeneses and their influence on fetal muscle development. Brain Dev (Tokyo) 1986; 8: 495-499.

27. Batton RR III, Jayaraman A, Ruggiero D, et al. Fastigial efferent projections in the monkey: An autoradiographic study. J Comp Neurol 1977; 174: 281-306.

28. Sarnat HB, Alcalá H. Human cerebellar hypoplasia. A syndrome of diverse causes. Arch Neurol 1980; 37: 300-305.

29. Gilman S. The mechanism of cerebellar hypotonia: An experimental study in the monkey. Brain 1969; 92: 621-638. 